\title{
Simultaneous determination of sulpiride and mebeverine by HPLC method using fluorescence detection: application to real human plasma
}

\author{
Mohamed I Walash, Mohie M Kh Sharaf El-din, Nahed M El-enany*, Manal I Eid and Shereen M Shalan
}

\begin{abstract}
A new simple, rapid and sensitive reversed-phase liquid chromatographic method was developed and validated for the simultaneous determination of sulpiride (SUL) and mebeverine Hydrochloride (MEB) in the presence of their impurities and degradation products. The separation of these compounds was achieved within 6 min on a 250 $\mathrm{mm}, 4.6 \mathrm{~mm}$ i.d., $5 \mathrm{~m}$ particle size Waters ${ }^{\circledR}$-C18 column using isocractic mobile phase containing a mixture of acetonitrile and $0.01 \mathrm{M}$ dihydrogenphosphate buffer (45:55) at $\mathrm{pH}=4.0$. The analysis was performed at a flow rate of $1.0 \mathrm{~mL} / \mathrm{min}$ with fluorescence-detection at excitation $300 \mathrm{~nm}$ and emission at $365 \mathrm{~nm}$. The concentrationresponse relationship was linear over a concentration range of $10-100 \mathrm{ng} / \mathrm{mL}$ for both MEB and SUL with a limit of detection $0.73 \mathrm{ng} / \mathrm{mL}$ and $0.85 \mathrm{ng} / \mathrm{mL}$ for MEB and SUL respectively. The proposed method was successfully applied for the analysis of both MEB and SUL in bulk with average recoveries of $100.22 \pm 0.757 \%$ and $99.96 \pm$ $0.625 \%$ respectively, and in commercial tablets with average recoveries of $100.04 \pm 0.93 \%$ and $100.03 \pm 0.376 \%$ for MEB and SUL respectively. The proposed method was successfully applied to the determination of MEB metabolite (veratic acid) in real plasma simultaneously with SUL. The mean\% recoveries $(n=3)$ for both MEB metabolite (veratic acid) and SUL were $100.36 \pm 2.92$ and $99.06 \pm 2.11$ for spiked human plasma respectively. For real human plasma, the mean\% recoveries $(n=3)$ were and respectively.
\end{abstract}

Keywords: Sulpiride, mebeverine, mebeverine metabolite (veratic acid), HPLC fluorimetric detection, pharmaceutical preparations and human plasma

\section{Introduction}

Mebeverine hydrochloride (MEB) 3,4-Dimethoxybenzoic acid 4- [ethyl[2-(4-methoxyphenyl)-1-methylethyl] amino]-butylester (Figure 1) is a potent direct antispasmodic acting mainly on the smooth muscles of the gastrointestinal tract and particularly effective against the colonic spasm [1].

Mebeverine undergoes rapid and extensive presystemic (first-pass) hydrolysis in the gut and/or the liver into mebeverine alcohol and veratic acid [1].

British Pharmacopoeia described a non aqueous titrimetric method for determination of MEB in pure form [2].

Sulpiride (SUL) 5-(Aminosulfonyl)-N-[(1-ethyl-2-pyrrolidinyl)methyl]-2-methoxy-benzamide (Figure 1) is the

\footnotetext{
* Correspondence: nelenany1@yahoo.com

Department of Analytical Chemistry, Faculty of Pharmacy, University of Mansoura, Mansoura, 35516, Egypt
}

most widely prescribed anti-psychotic drug. It is a selective dopamine $\mathrm{D}_{2}$ antagonist with antidepressant activities it exerts a mood elevating effect and antiemetic action [1].

Regarding SUL, British Pharmacopoeia described a non aqeous titrimetric method for determination of SUL in pure form [2].

Combination of MEB and SUL is used for treatment gastrointestinal and colic spasms which are a consequence of psychosomatic manifestation of nervous tention, mental stress or anxiety. MEB and SUL were determined in their binary mixture via derivative spectroscopy $[3,4]$, first derivative synchronous fluorescence spectroscopy [5]. TLC- densitometry [4], HPLC [4-6] and chemometric techniques [7].

The aim of the present study is to establish and develop a novel, sensitive and selective HPLC method for simultaneous determination of MEB and SUL either 
<smiles>CCN(CCCCOC(=O)c1ccc(C)c(OC)c1)C(C)Cc1ccc(OC)cc1</smiles>

Mebeverine<smiles>CCN1CCCC1CNC(=O)c1cc(S(N)(=O)=O)ccc1OC</smiles>

Sulpiride

Figure 1 Structural formulae of the studied drugs.

per se or in pharmaceutical preparations and in real human plasma as SUL and MEB metabolite (veratic acid). However, to the best of our knowledge, no analytical methods have been reported for the simultaneous determination of all compounds in the presence of their impurities and degradation products, which might interfere with the analysis of the active ingredients

\section{Experimental}

\section{Chromatographic conditions}

- HPLC experiments were performed with a Merck Hitachi L- 7100 chromatograph equipped with a Rheodyne injector valve with a $20 \mu \mathrm{L}$ loop. The detection of analytes was monitored at emmision $365 \mathrm{~nm}$ after excitation at $300 \mathrm{~nm}$ by L-7485 fluorescense-detector (Darmstadt, Germany). Chromatograms were recorded on a Merck Hitachi D-7500 integrator. Mobile phases were degassed using Merck L 7612 solvent degasser. The separation of these compounds was achieved on Waters ${ }^{\circledR}$-C18 column $(250 \mathrm{~mm}, 4.6 \mathrm{~mm}$ i.d., $5 \mathrm{~m}$ particle size) using isocractic mobile phase containing a mixture of acetonitrile and $0.01 \mathrm{M}$ dihydrogenphosphate buffer 45:55 (v/v). The analysis was performed at a flow rate of $1 \mathrm{mLmin}^{-1}$. The $\mathrm{pH}$ of the buffer was adjusted with orthophosphoric acid. Prior to any analysis, the mobile phase was filtered using $0.45 \mu \mathrm{m}$ filters. The system was equilibrated with the mobile phase before injection.

\section{Reagents and chemicals}

-Working reference standard of SUL and MEB were kindly supplied by RAMEDA (The Tenth of Ramadan) Co. for Pharmaceutical Industries \& Diagnostic Reagents, $6^{\text {th }}$ of October City, Egypt.

-Colona ${ }^{\circledR}$ tablets (Batch No. 09425, labelled to contain $25 \mathrm{mg}$ SUL and $100 \mathrm{mg}$ MEB per tablet) are from RAMEDA (The Tenth of Ramadan) Co. for Pharmaceutical Industries \& Diagnostic Reagents, $6^{\text {th }}$ of October City, Egypt.

- Acetonitrile- HPLC grade (Riedel-de Haen, Germany), Phosphoric acid 85\% (Riedel-de Haen, Germany).
Analytical grade potassium dihydrogenphosphate and orthophosphoric acid were obtained from Prolabo (Paris, France). HPLC grade methanol $(\mathrm{MeOH})$ was obtained from Prolabo (Paris, France).

- SUL impurities, 2-methoxy-5-sulfamoyl benzoic acid methyl ester (sules) (CAS No. 33045-52-2) and 2-aminomethyl-1-ethylpyrrolidine (sulam) (CAS No. 26116-12-1) were imported from Wuhan Yuancheng Technology Development Co. Ltd., China.

\section{Preparation of standard solutions}

Preparation of stock standard solutions Stock standard solutions of MEB, SUL and SUL impurities (200 $\mu \mathrm{g} / \mathrm{mL}$ each) were prepared by accurately weighed 10.0 $\mathrm{mg}$ of each of MEB and SUL and transferred to $50 \mathrm{ml}$ measuring flasks. The compounds were separately dissolved in $50 \mathrm{ml}$ of methanol. The stock solutions were further diluted with the mobile phase to obtain the working concentration ranges. The standard solutions were kept in the refrigerator and were found to be stable for 10 days.

Preparation and separation of the hydrolytic degradation products of $M E B \quad 0.5 \mathrm{gm}$ MEB powder was transferred into $100 \mathrm{ml}$ stoppered flask. $100 \mathrm{~mL} 1 \mathrm{~N}$ $\mathrm{NaOH}$ dissolved in methanol was added and the solution was heated at $45^{\circ} \mathrm{C}$ for $12 \mathrm{hrs}$ till complete degradation of MEB (investigated by the disappearance of MEB spot upon applying qualitative TLC). The solution was left to evaporate under reduced pressure to residue, 30 $\mathrm{ml}$ distilled water was added and the oily part was extracted with $60 \mathrm{ml}$ ether in divided portions. The ether extract was washed with $20 \mathrm{ml}$ distilled water in two fractions and then the ethereal layer was let to evaporate at room temperature where a colorless oily residue appeared of 4-(ethyl [2-(4-methoxyphenyl)-1methylethyl] amino) butan-1-ol (mebOH) [6]. The primarily separated aqueous layer was acidified with $5 \mathrm{~N}$ $\mathrm{HCl}$ just till acidic to litmus, where a heavy white precipitate of veratic acid was produced, which was then filtered and washed with $30 \mathrm{ml}$ distilled water added in divided portions, The white needles of veratic acid were dried in the oven at $90^{\circ} \mathrm{C}$ for $1 \mathrm{hr}$ [6]. IR and Mass 
spectra were obtained to confirm the identity of the separated degradation products of MEB (veratic acid) as shown in Figure 2.

Stock standard solution of veratic acid $(200 \mu \mathrm{g} / \mathrm{mL}$ each) was prepared by accurately weighed $10.0 \mathrm{mg}$ of veratic acid and transferred to $50 \mathrm{ml}$ measuring flask. The compound was dissolved in $50 \mathrm{~mL}$ of methanol.
The stock solution was further diluted with the mobile phase to obtain the working standard solution.

\section{Construction of the calibration curves}

Aliquots of MEB and SUL covering the working concentration range 10-100 $\mathrm{ng} / \mathrm{mL}$ for each of MEB and SUL were quantitatively transferred into a series of $10 \mathrm{~mL}$ volumetric flasks, after being diluted to $10 \mathrm{~mL}$ with the

A)

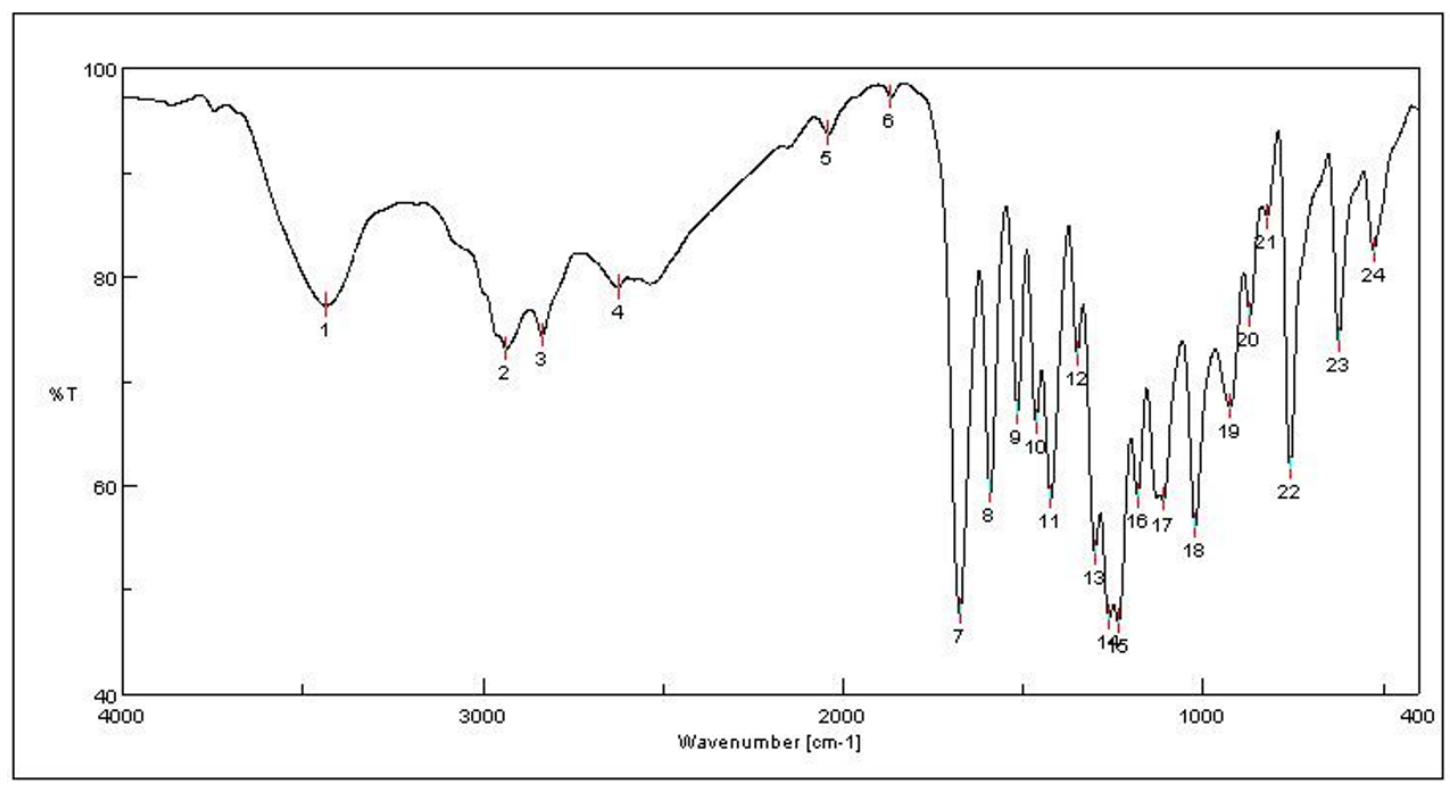

B)

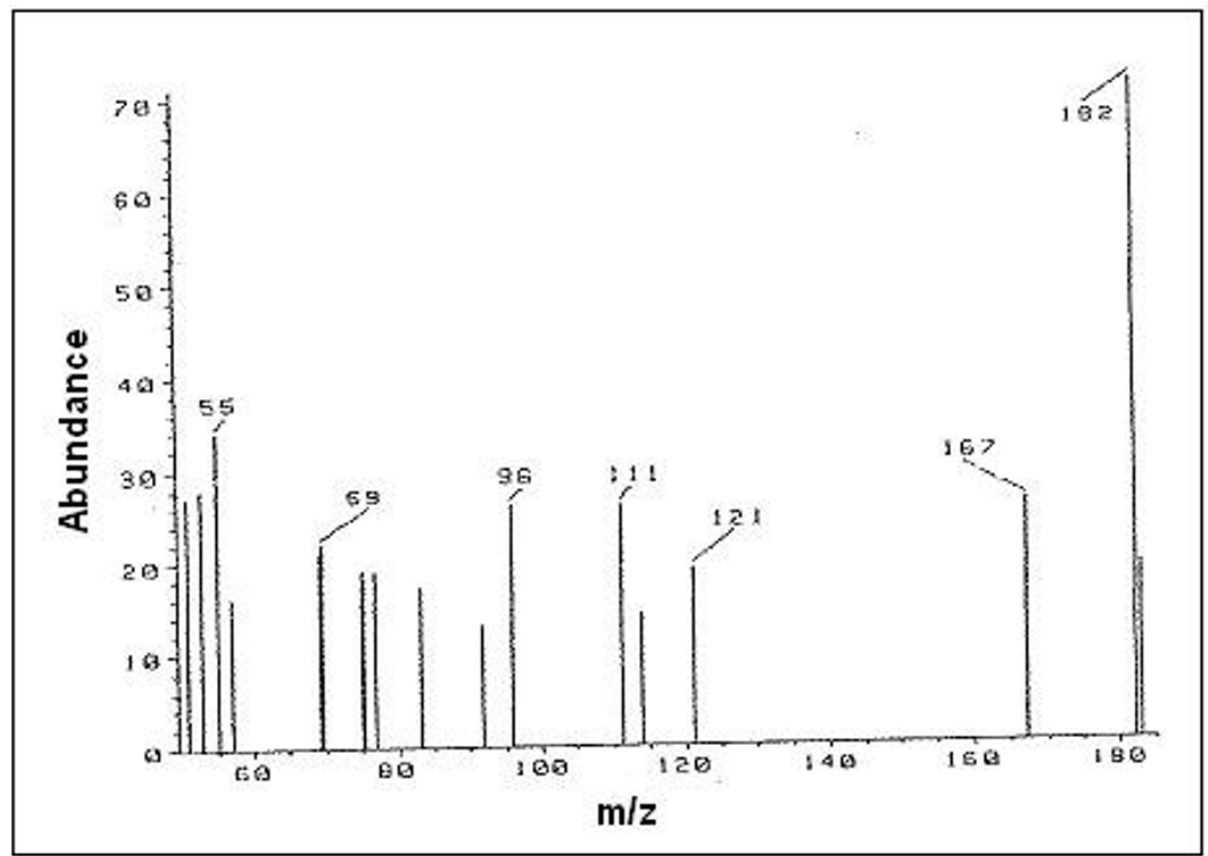

Figure 2 a: IR spectrum of veratic acid. b: Mass spectrum of veratic acid (Mol. Wt. = 182). 
mobile phase ( $\mathrm{pH}=4) .20 \mu \mathrm{L}$ aliquots were injected (in triplicate) and calibration curve was constructed by plotting the peak area ratio between a drug and the other drug as internal standard against the final concentration of drugs in $\mathrm{ng} / \mathrm{mL}$, alternatively, the corresponding regression equations were derived.

\section{Procedure for the synthetic mixture}

Aliquot volumes of MEB and SUL standard solutions in the ratio of $4: 1$ were transferred into a series of $10 \mathrm{~mL}$ volumetric flasks. The flasks completed to the volume with the mobile phase. The procedure described under section 2.4 was performed.

\section{Procedure for commercial tablets}

10 film coated tablets were bleached with methanol swab and pulverized well. A weighed quantity of the powder equivalent to $100 \mathrm{mg}$ MEB and $25 \mathrm{mg}$ of SUL (in their pharmaceutical ratio of 4:1) was transferred into a small conical flask and extracted with $3 \times 30 \mathrm{~mL}$ of methanol. The extract was filtered into a $100 \mathrm{~mL}$ volumetric flask. The conical flask was washed with few milliliters of methanol. The washings were passed into the same volumetric flask and completed to the volume with the same solvent. Aliquots covering the working concentration range were transferred into $10 \mathrm{~mL}$ volumetric flasks. The recommended procedure under "Calibration Curve" was performed. The nominal content of the tablets were determined either from a previously plotted calibration graph or using the corresponding regression equation.

\section{Procedure for spiked human plasma}

Suitable aliquots of mixture of MEB metabolite (veratic acid) and SUL stock solutions containing 10.0-50.0 ng/ $\mathrm{mL}$ and $10.0-100.0 \mathrm{ng} / \mathrm{mL}$ respectively were transferred into centrifugation tubes. $1.0 \mathrm{ml}$ of human plasma was added to each tube. Then, alkalinization was achieved by addition of $0.1 \mathrm{~mL}$ of $\mathrm{NaOH}(1.0 \mathrm{M})$ and the tubes were shaken for $1 \mathrm{~min}$. The samples were mixed well using a vortex mixer and then extracted with $3 \times 3 \mathrm{~mL}$ of ethyl acetate/dichloromethane $(5: 1 \mathrm{v} / \mathrm{v})$ by centrifugation for $5 \mathrm{~min}$ at $4000 \mathrm{rpm}$. The organic layer was transferred into an evaporating dish and evaporated till dryness. The residue was reconstituted in $3 \mathrm{~mL}$ methanol [8]. The procedure described under calibration curve was followed. The nominal content of the drug was determined from the previously plotted calibration graph or using the corresponding regression equation.

\section{Procedure for real human plasma}

Three healthy volunteers (women around 35 years old) were administered Colona ${ }^{\circledR}$ tablets after 8 hours fasting. Further, $5 \mathrm{~mL}$ blood samples were drawn at different time intervals at $0.5,1.0,1.5,2.0,2.5,3.0,3.5,4.0,4.5$, 5.0 and $6.0 \mathrm{hr}$ into tubes containing $0.5 \mathrm{ml}$ of 2\% EDTA solution to prevent blood coagulation. The blood was processed to plasma by centrifugation at $4000 \mathrm{rpm}$ and $15 \mathrm{~min}$. the supernatant plasma samples transferred into test tubes and the procedure mentioned above was followed for the monitoring of drug concentration in plasma.

\section{Results and discussion \\ Chromatography}

The proposed method permits the separation of MEB and SUL from degradation product and impurity. Figure 3 shows a chromatogram indicating good resolution of $\operatorname{MEB}\left(t_{R}=5.0\right.$ min.) and SUL $\left(t_{R}=2.4\right)$ in pure form and in tablet extract, whereas Figure 4 show good resolution of MEB, MEB metabolite (veratic acid), SUL and SUL impurity (sules).

In an attempt to optimize the separation of MEB and SUL and their impurities and degradation products in bulk and plasma, the effects of some chromatographic parameters such as mobile phase composition and $\mathrm{pH}$ of the buffer solution were investigated.

\section{Effect of the mobile phase composition Type of Organic Modifier}

Acetonitrile was replaced by methanol but it did not give good resolved peaks. Acetonitrile was the organic modifier of choice giving symmetrical narrow peaks.

\section{Ratio of Organic Modifier}

The effect of changing the ratio of organic modifier on the selectivity and

retention times of the test solutes was investigated using mobile phases containing concentrations of 40$75 \%$ for acetonitrile. Table 1 shows that $45 \%$

acetonitrile was the best one giving well resolved peaks and highest number of theoretical plates. Ratios less than $45 \%$ resulted in peaks with very long unacceptable retention times, whereas ratios higher than $75 \%$ resulted in precipitation in the mobile phase.

\section{Effect of $p H$}

The effect of changing the $\mathrm{pH}$ of the mobile phase on the selectivity and retention times of the test solutes was investigated using mobile phases of $\mathrm{pH}$ ranging from 3.0-5. Table 1 illustrated that a $\mathrm{pH}$ of 4.0 was the most appropriate one giving well-resolved peaks and highest number of theoretical plates. pHs higher than 5.0 produced precipitation in the mobile phase.

\section{lonic Strength of Buffer}

The effect of changing the ionic strength of phosphate buffer on the selectivity and retention times of the test solutes was investigated using mobile phases containing concentration of $0.0075-0.04 \mathrm{M}$ of phosphate buffer. Table 1 shows that $0.01 \mathrm{M}$ phosphate buffer was found to be the most suitable giving best resolution and highest number of theoretical plates. 

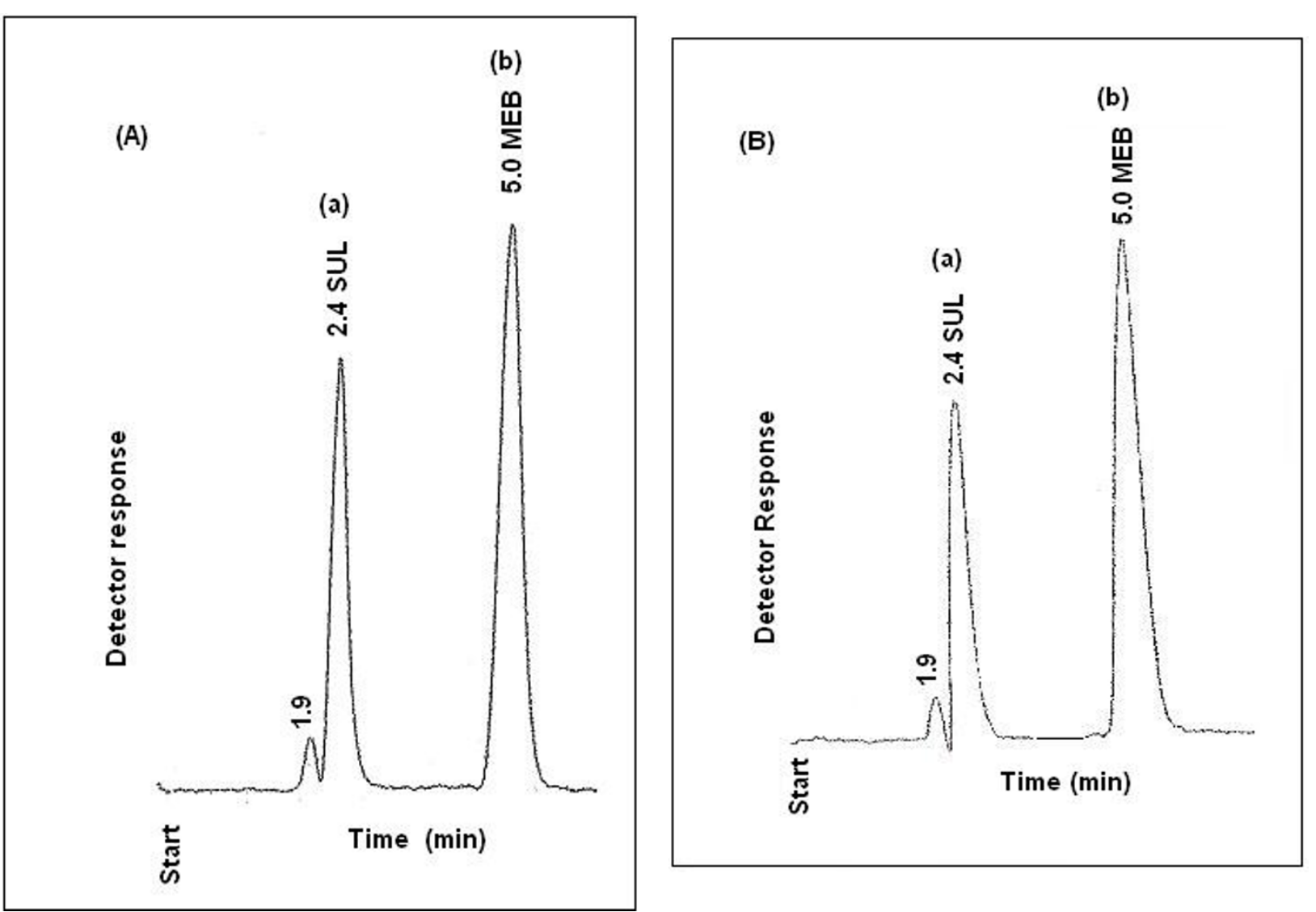

Figure 3 HPLC typical chromatograms of: (A) Synthetic mixture of [(a) $25 \mathrm{ng} / \mathrm{mLSUL}$, (b) $100 \mathrm{ng} / \mathrm{mL}$ MEB]. (B) Chromatogram of Colona ${ }^{\circledR}$ tablet extract [(a) $25 \mathrm{ng} / \mathrm{mL}$ SUL, (b) $100 \mathrm{ng} / \mathrm{mL}$ MEB] under the described chromatographic conditions.

\section{Effect of Flow Rate}

The effect of flow rate on the formation and separation of peaks of the studied compounds was studied and a flow rate of $1 \mathrm{~mL} / \mathrm{min}$ was optimal for good separation in a reasonable time (Table 1 ).

\section{Validation of the Method}

\section{Concentration Ranges and Calibration Graphs}

Under the above described experimental conditions, a linear relationships was established by plotting peak area ratio for MEB to $0.1 \mu \mathrm{g} / \mathrm{mL}$ SUL as internal standard against MEB concentrations and on the other hand, plot peak area ratio for SUL to $0.1 \mu \mathrm{g} / \mathrm{mL} \mathrm{MEB}$ as internal standard against SUL concentrations,. The concentration range was found to be $10-100 \mathrm{ng} / \mathrm{mL}$ for each drug. Linear regression analysis of the data gave the following equations:

$$
\begin{aligned}
& P=0.018+0.04 C \quad(r=0.9999) \text { for MEB. } \\
& P=0.024+0.001 C \quad(r=0.9999) \text { for SUL. }
\end{aligned}
$$

where: $C$ is the concentration of MEB or SUL in ng/ $\mathrm{mL}$ and $\mathrm{P}$ is the peak area ratio. The high value of the correlation coefficient ( $r$-values $>0.999)$ with small intercept indicate the good linearity of the calibration graphs. Statistical analysis of the data gave small values of the standard deviation of the residuals, and the\% relative error, [9] as shown in table 2.

\section{Limit of Quantitation and Limit of Detection}

The limits of quantification (LOQ) was calculated according to ICH Q2B recommendations [10]. The limits of detection (LOD) was also calculated according to ICH Q2B recommendations [10]. The results of LOD and LOQ of MEB and SUL respectively are abridged in Table 2.

LOQ and LOD were calculated according to the following equations [10]:LOQ $=10 \sigma / S$

$\mathrm{LOD}=3.3 \sigma / \mathrm{S}$

Where, $\sigma$ is the standard deviation of the intercept of regression line and $S$ is the slope of regression line of the calibration curve. Statistical analysis [9] of the results, obtained by the proposed and the reference method [4] using Student's t-test and variance ratio Ftest, shows no significant difference between the performance of the two methods regarding the accuracy and precision, respectively (Table 3 ). 

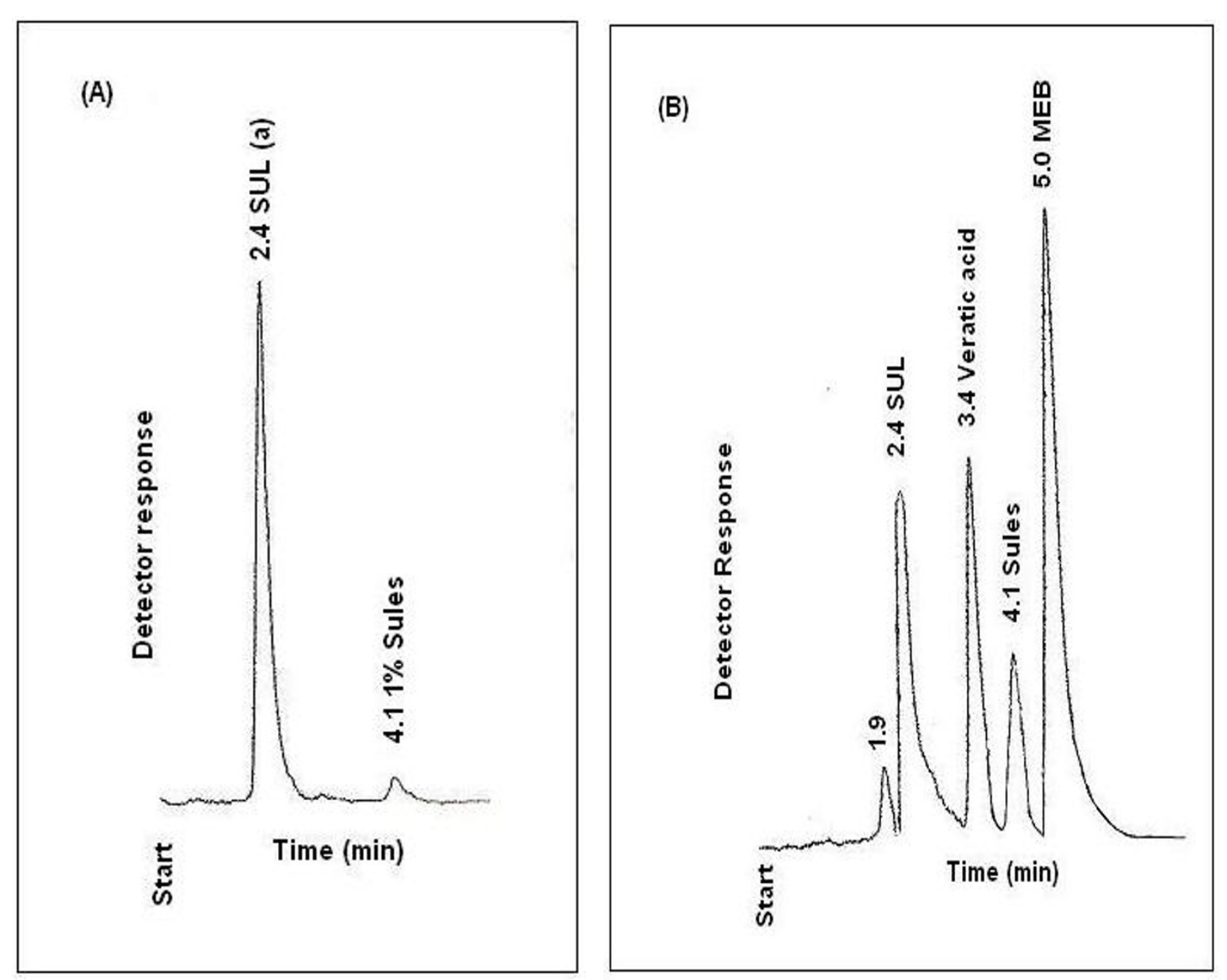

Figure 4 (A) HPLC typical chromatogram of SUL (100 ng/mL) in presence of its sules impurity (1.0\%). (B) HPLC typical chromatogram of separated SUL $(25 \mathrm{ng} / \mathrm{mL})$, veratic acid $(10 \mathrm{ng} / \mathrm{mL})$, sules $(100 \mathrm{ng} / \mathrm{mL})$ and MEB $(100 \mathrm{ng} / \mathrm{mL})$.

The reference method is based on HPLC separation of the two drugs on a reversed phase, Bondapak $\mathrm{CN}$ column and UV detection was done at $243 \mathrm{~nm}$ using buclizine hydrochloride as internal standard [4].

\section{Accuracy and Precision}

Repeatability The repeatability was evaluated by applying the proposed method for the determination of three concentrations of MEB and SUL in pure forms on three successive times, and the results are abridged in Table 4. The low \%Error and low \% RSD indicates high accuracy and high precision of the proposed method respectively.

Intermediate precision Intermediate precision was performed through replicate analysis of MEB and SUL in pure form. The results are shown in Table 4, for a period of 3 successive days.

\section{Application of the method}

\section{Pharmaceutical Applications}

Selectivity The proposed method was applied for the determination of the studied drugs in their co-formulated tablets. The specificity of the method was investigated by observing any interference encountered from the common tablet excepients, such as lactose, gelatin, magnesium stearate and starch. These excepients did not interfere with the proposed method (Table 5). The average percent recoveries of different concentrations were based on the average of three replicate determinations. The results shown in Table 4 are in good agreement with those obtained with the reference method [4]. Figure 3 shows a chromatogram indicating good resolved peaks of MEB and SUL.

Degradation product of MEB (veratic acid) and impurity of SUL (sules) of is easily detectable and can be 
Table 1 Effect of experimental parameters on the number of theoretical plates of the studied compounds

\begin{tabular}{|c|c|c|c|c|c|}
\hline \multirow[t]{2}{*}{ Parameter } & & \multicolumn{2}{|c|}{ No. of theoretical plates $(\mathrm{N})$} & \multicolumn{2}{|c|}{ Resolution (Rs) } \\
\hline & & MEB & SUL & MEB & SUL \\
\hline \multirow[t]{7}{*}{ Ratio of organic modifier $A / B$} & $40 / 60$ & 1199 & 2521 & 3.20 & 0.345 \\
\hline & $45 / 55$ & 3407 & 4691 & 6.00 & 3.95 \\
\hline & $50 / 50$ & 2867 & 1824 & 5.75 & 1.77 \\
\hline & $55 / 45$ & 1658 & 911 & 3.97 & 1.20 \\
\hline & $60 / 40$ & 1255 & 1348 & 3.97 & 1.46 \\
\hline & $70 / 30$ & 1946 & 834 & 4.90 & 6.19 \\
\hline & $75 / 25$ & 1487 & 825 & 4.20 & 0.99 \\
\hline \multirow[t]{5}{*}{$\mathrm{pH}$} & 3.0 & 2687 & 1778 & 5.04 & 1.55 \\
\hline & 3.5 & 1138 & 1510 & 3.50 & 1.52 \\
\hline & 4.0 & 3462 & 4659 & 6.16 & 3.70 \\
\hline & 4.5 & 1716 & 2366 & 5.10 & 3.10 \\
\hline & 5.0 & 1345 & 1630 & 5.33 & 3.10 \\
\hline \multirow[t]{5}{*}{ lonic strength of phosphate buffer [M] } & 0.0075 & 2935 & 2315 & 5.08 & 2.24 \\
\hline & 0.01 & 3451 & 4632 & 6.16 & 3.72 \\
\hline & 0.02 & 1614 & 1251 & 5.60 & 2.62 \\
\hline & 0.03 & 1982 & 1150 & 6.20 & 2.50 \\
\hline & 0.04 & 1394 & 950 & 5.30 & 2.40 \\
\hline \multirow[t]{5}{*}{ Flow rate $\mathrm{mL} / \mathrm{min}$} & 0.50 & 1297 & 1783 & 3.6 & 1.5 \\
\hline & 0.75 & 2356 & 3252 & 5.20 & 2.50 \\
\hline & 1.00 & 3442 & 4621 & 6.20 & 3.90 \\
\hline & 1.20 & 1864 & 2534 & 4.75 & 3.10 \\
\hline & 1.50 & 1534 & 1963 & 5.80 & 3.40 \\
\hline
\end{tabular}

determined quantitatively as shown Figure 4. Therefore, the proposed method can be used for the quality control of the tablets.

\section{Biological applications}

The high sensitivity of the proposed method allowed the determination of MEB metabolite and SUL in biological fluids by HPLC method. The method was further applied to the in-vivo determination of both drugs in real human plasma. Sulpiride is absorbed from gastrointestinal tract. Following oral ingestion of a single oral dose of $50 \mathrm{mg}$ of SUL, a peak plasma concentration of

Table 2 Performance data of the proposed method

\begin{tabular}{ccc}
\hline Parameter & Mebeverine & Sulpiride \\
\hline Concentration range $(\mathrm{ng} / \mathrm{mL})$ & $10-100$ & $10-100$ \\
Limit of detection $(\mathrm{LOD})(\mathrm{ng} / \mathrm{mL})$ & 0.85 & 0.73 \\
Limit of quantification $(\mathrm{LOQ})(\mathrm{ng} / \mathrm{mL})$ & 2.57 & 2.21 \\
Correlation coefficient $(\mathrm{r})$ & 0.9999 & 0.9999 \\
Slope & 0.04 & 0.001 \\
Intercept & 0.018 & 0.024 \\
standard deviation of the residuals $\left(\mathrm{S}_{\mathrm{y} / \mathrm{x}}\right)$ & 0.017 & 0.0005 \\
standard deviation of the intercept $\left(\mathrm{S}_{\mathrm{a}}\right)$ & 0.012 & 0.0003 \\
standard deviation of the slope $\left(\mathrm{S}_{\mathrm{b}}\right)$ & $2.23 \times 10^{-5}$ & $7.0 \times 10^{-7}$ \\
\%RSD & 0.756 & 0.626 \\
\% Error & 0.267 & 0.221 \\
\hline
\end{tabular}

$\mathrm{S}_{\mathrm{y} / \mathrm{x},}$ Standard deviation of the residuals; $\mathrm{S}_{\mathrm{a}}$, Standard deviation of the intercept; $S_{b}$ Standard deviation of the slope
$0.03-0.60 \mathrm{mg} / \mathrm{L}$ (mean $0.18 \mathrm{mg} / \mathrm{L}$ ) is attained in about 47 hours [8]. This value lies within the working concentration range of the proposed method.

After oral administration of mebeverine HCI (270 mg) to fasted human volunteers, measurable concentrations of the drug were not found in plasma. By contrast, the metabolite veratric acid achieved considerable concentrations (mean peak plasma concentration of $13.5 \mu \mathrm{g} /$ $\mathrm{mL}$ at (40-80 $\mathrm{min})$ [11]. Veratic acid (MEB metabolite) is also highly fluorescent compound and the second metabolite is mebeverine alcohol which is non-fluorescent at the studied $\mathrm{pH} 4$ [12]. However, after oral administration of mebeverine HCI (2 mg), only traces of mebeverine were found in plasma with simultaneous appearance of veratic acid. Veratric acid was achieved with considerable concentrations (mean peak plasma concentration of $0.90 \mu \mathrm{g} / \mathrm{mL}$ at $(15 \mathrm{~min}-4 \mathrm{~h})$. The mean percentage recoveries, \% Error and \% RSD are abridged in Table 6. The results show that mebeverine undergoes rapid and extensive first-pass metabolism involving hydrolysis of the ester function, as shown in Figure 5 and that very trace circulating concentrations of the parent drug are found in humans [12].

The typical chromatograms for the separation of the MEB, veratic acid and SUL in real plasma are illustrated in Figure 6. The plasma samples obtained from the volunteers were investigated using the previously 
Table 3 Application of the proposed method to the determination of the studied drugs in the pure form

\begin{tabular}{|c|c|c|c|c|}
\hline Parameter & $\begin{array}{l}\text { Concentration taken } \\
(\mathrm{ng} / \mathrm{mL})\end{array}$ & $\begin{array}{l}\text { Concentration found } \\
\text { (ng/mL) }\end{array}$ & $\%$ Found & Reference method \\
\hline \multirow[t]{8}{*}{ 1- MEB } & 10 & 10.06 & 100.56 & 100.46 \\
\hline & 20 & 20.29 & 101.44 & 99.53 \\
\hline & 30 & 30.12 & 100.40 & 100.15 \\
\hline & 40 & 39.74 & 99.36 & \\
\hline & 50 & 49.78 & 99.55 & \\
\hline & 60 & 60.01 & 100.02 & \\
\hline & 80 & 79.46 & 99.33 & \\
\hline & 100 & 100.54 & 100.54 & \\
\hline$X^{\prime}$ & & & 100.22 & 100.04 \\
\hline \pm S.D. & & & 0.757 & 0.473 \\
\hline t-test & & $0.0 .379(1.833)$ & & \\
\hline F-value & & $2.55(4.74)$ & & \\
\hline \multirow[t]{8}{*}{ 2- SUL } & 10 & 10.08 & 100.78 & 100.9 \\
\hline & 20 & 19.80 & 99.00 & 99.0 \\
\hline & 30 & 30.10 & 100.34 & 100.3 \\
\hline & 40 & 40.05 & 100.13 & \\
\hline & 50 & 50.00 & 100.00 & \\
\hline & 60 & 59.71 & 99.52 & \\
\hline & 80 & 80.43 & 100.53 & \\
\hline & 100 & 99.82 & 99.825 & \\
\hline$X^{\prime}$ & & & 99.96 & 100.0 \\
\hline \pm S.D. & & & 0.390 & 0.92 \\
\hline t-test & & $0.08(1.833)$ & & \\
\hline F-value & & $2.41(4.74)$ & & \\
\hline
\end{tabular}

Values between parenthesis are the tabulated $t$ and $F$ values, respectively at $p=0.05$.

Table 4 Application of the proposed method for determination of the studied drugs in their synthetic mixtures and in co-formulated tablets

\begin{tabular}{|c|c|c|c|c|c|c|}
\hline \multirow[t]{2}{*}{ Sample } & \multicolumn{2}{|c|}{$\begin{array}{c}\text { Concentration taken } \\
(\mathrm{ng} / \mathrm{mL})\end{array}$} & \multicolumn{2}{|c|}{ Concentration found (ng/mL) } & \multicolumn{2}{|c|}{ Recovery \% } \\
\hline & MEB & SUL & MEB & SUL & MEB & SUL \\
\hline \multirow[t]{4}{*}{ 1-MEB and SUL mixture } & 40 & 10 & 40.23 & 9.96 & 100.58 & 99.59 \\
\hline & 60 & 15 & 59.38 & 15.12 & 98.97 & 100.82 \\
\hline & 80 & 20 & 80.53 & 19.89 & 100.66 & 99.47 \\
\hline & 100 & 25 & 99.86 & 25.03 & 99.86 & 100.11 \\
\hline$X^{\prime}$ & & & & & 100.01 & 99.99 \\
\hline $\pm S . D$. & & & & & 0.787 & 0.61 \\
\hline$\%$ RSD & & & & & 0.786 & 0.61 \\
\hline \%Error & & & & & 0.278 & 0.300 \\
\hline \multicolumn{7}{|l|}{ 2-Colona ${ }^{\circledR}$ tablets $^{\text {a }}$} \\
\hline (MEB 100 mg +SUL 25 mg/tab.) & 40 & 10 & 40.18 & 10.06 & 100.45 & 100.65 \\
\hline \multirow[t]{3}{*}{ Batch \# 09425.} & 60 & 15 & 60.26 & 14.97 & 100.44 & 99.77 \\
\hline & 80 & 20 & 78.92 & 19.86 & 98.65 & 99.30 \\
\hline & 100 & 25 & 100.63 & 25.11 & 100.63 & 100.42 \\
\hline$X^{\prime}$ & & & & & 100.04 & 100.03 \\
\hline \pm S.D. & & & & & 0.930 & 0.614 \\
\hline$\%$ RSD & & & & & 0.933 & 0.614 \\
\hline \%Error & & & & & 0.467 & 0.307 \\
\hline
\end{tabular}

-Each result is the average of three separate determinations.

- ${ }^{\text {a }}$ Product of Rameda Co. for Pharmaceutical Industries and Diagnostic Reagents $6^{\text {th }}$ of October City. Egypt. 
Table 5 Validation of the proposed method for determination of MEB and SUL raw materials using the proposed method

\begin{tabular}{|c|c|c|c|}
\hline Concentration added $(\mathrm{ng} / \mathrm{mL})$ & $\%$ recovery & $\%$ RSD & $\%$ Error \\
\hline \multicolumn{4}{|l|}{ MEB } \\
\hline \multicolumn{4}{|l|}{ Intra-day } \\
\hline 40 & $100.85 \pm 0.636$ & 0.630 & 0.364 \\
\hline 60 & $100.37 \pm 0.490$ & 0.488 & 0.281 \\
\hline 80 & $100.2 \pm 0.854$ & 0.852 & 0.491 \\
\hline \multicolumn{4}{|l|}{ Inter-day } \\
\hline 40 & $99.75 \pm 0.921$ & 0.925 & 0.534 \\
\hline 60 & $99.08 \pm 0.589$ & 0.594 & 0.343 \\
\hline 80 & $100.53 \pm 0.650$ & 0.646 & 0.373 \\
\hline \multicolumn{4}{|l|}{ SUL } \\
\hline \multicolumn{4}{|l|}{ Intra-day } \\
\hline 10 & $100.23 \pm 0.737$ & 0.735 & 0.424 \\
\hline 15 & $101.03 \pm 1.023$ & 1.012 & 0.584 \\
\hline 20 & $100.06 \pm 0.573$ & 0.572 & 0.330 \\
\hline \multicolumn{4}{|l|}{ Inter-day } \\
\hline 10 & $98.96 \pm 0.824$ & 0.832 & 0.480 \\
\hline 15 & $99.99 \pm 0.961$ & 0.961 & 0.554 \\
\hline 20 & $100.78 \pm 0.762$ & 0.756 & 0.436 \\
\hline
\end{tabular}

N.B. Each result is the average of three separate determinations.

obtained calibration graph or regression equations and the results obtained are shown in Figure 7 showing maximum plasma levels are reached after 3.5 hours for
SUL and veratic acid. Hence, the proposed method allows for the therapeutic drug monitoring for MEB and SUL mixture level in plasma.

Table 6 Application of the proposed method for determination of the studied drugs in spiked and real human plasma

\begin{tabular}{|c|c|c|c|c|c|c|}
\hline \multirow[t]{2}{*}{ Sample } & \multicolumn{2}{|c|}{ Concentration taken $(\mathrm{ng} / \mathrm{mL})$} & \multicolumn{2}{|c|}{ Concentration found (ng/mL) } & \multicolumn{2}{|c|}{ Recovery \% } \\
\hline & Veratic acid & SUL & Veratic acid & SUL & Veratic acid & SUL \\
\hline \multicolumn{7}{|l|}{ 1-Spiked plasma sample } \\
\hline \multirow[t]{3}{*}{ a- Intra-day precision } & 10 & 10 & 10.32 & 9.62 & 103.19 & 96.23 \\
\hline & 25 & 50 & 24.34 & 51.04 & 97.36 & 102.09 \\
\hline & 50 & 100 & 50.28 & 99.50 & 100.55 & 99.50 \\
\hline$x^{\prime}$ & & & & & 100.36 & 99.27 \\
\hline \pm S.D. & & & & & 2.92 & 2.95 \\
\hline$\%$ RSD & & & & & 2.91 & 2.95 \\
\hline \%Error & & & & & 1.68 & 1.69 \\
\hline \multirow[t]{3}{*}{ b- Inter- day precision } & 50 & 100 & 50.56 & 95.32 & 101.12 & 95.30 \\
\hline & 50 & 100 & 51.10 & 98.57 & 102.20 & 98.57 \\
\hline & 50 & 100 & 49.95 & 101.24 & 99.90 & 101.24 \\
\hline$X^{\prime}$ & & & & & 101.07 & 98.37 \\
\hline \pm S.D. & & & & & 1.15 & 2.97 \\
\hline$\%$ RSD & & & & & 1.13 & 3.02 \\
\hline \%Error & & & & & 0.65 & 1.74 \\
\hline \multirow[t]{3}{*}{ 2- Real plasma sample } & 100 & 100 & 91.87 & 92.48 & 91.87 & 92.48 \\
\hline & 100 & 100 & 90.12 & 93.76 & 90.12 & 93.76 \\
\hline & 100 & 100 & 86.25 & 87.98 & 86.25 & 87.98 \\
\hline$x^{-}$ & & & & & 89.41 & 91.40 \\
\hline \pm S.D. & & & & & 2.87 & 3.03 \\
\hline$\%$ RSD & & & & & 3.21 & 3.321 \\
\hline \%Error & & & & & 1.85 & 1.91 \\
\hline
\end{tabular}


<smiles>CCN(CCCCOC(=O)c1ccc(OC)c(OC)c1)C(C)Cc1ccc(OC)cc1</smiles>

mebeverine<smiles>COc1ccc(CC(C)N(C)CCCCO)cc1</smiles>

mebeverine alcohol<smiles>COc1ccc(CC(C)N(C)CCCC(=O)O)cc1</smiles>

mebeverine acid

Figure 5 In vivo hydrolysis of mebeverine into mebeverine alcohol and veratic acid and the subsequent oxidation of mebeverine alcohol to mebeverine acid.
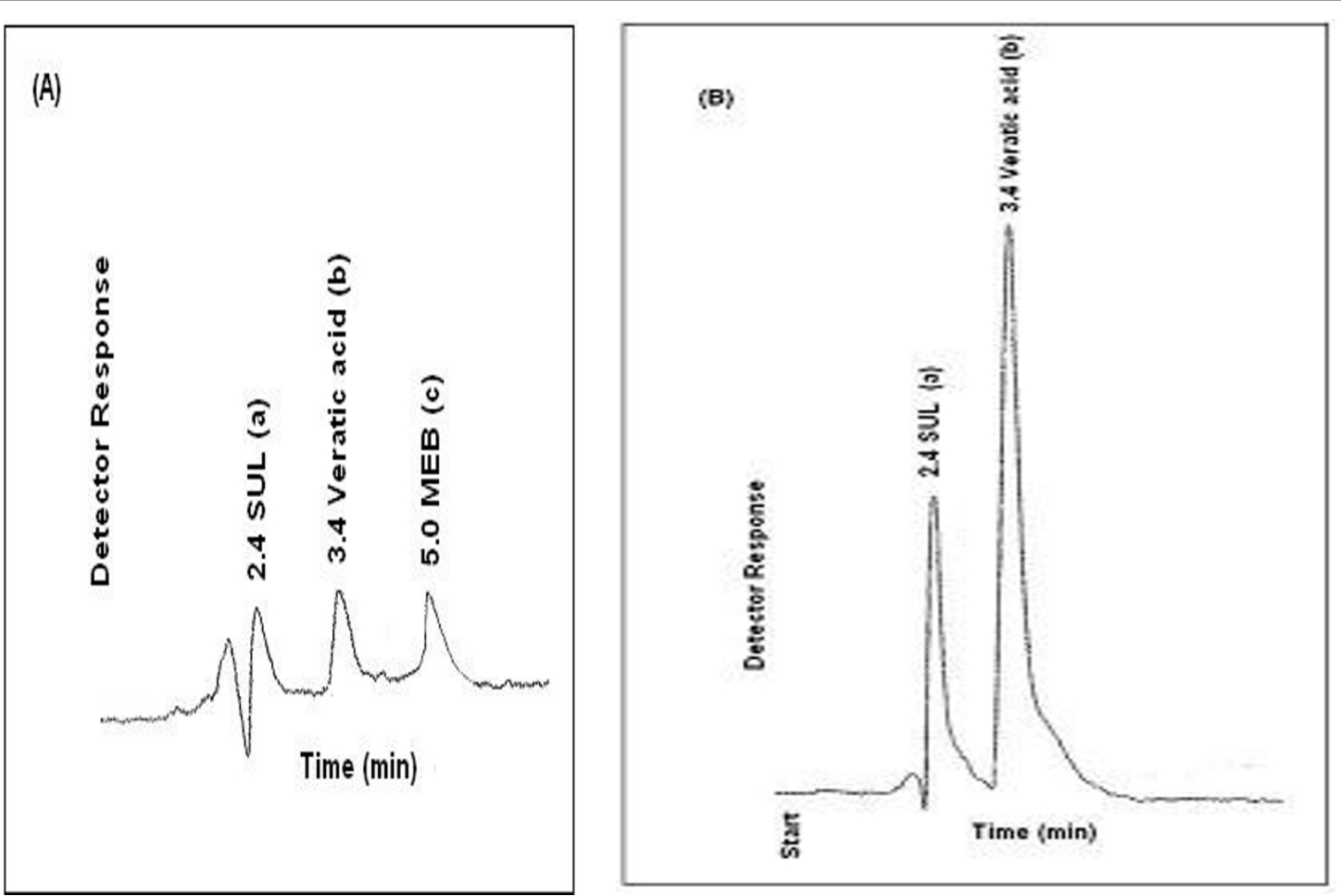

Figure 6 (A) Plasma samples obtained $1.0 \mathrm{hr}$ after oral administration of Colona ${ }^{\circledR}$ tablet under the chromatographic conditions. (B) Plasma samples obtained $3.5 \mathrm{hr}$ after oral administration of Colona ${ }^{\circledR}$ tablet under the chromatographic conditions. 


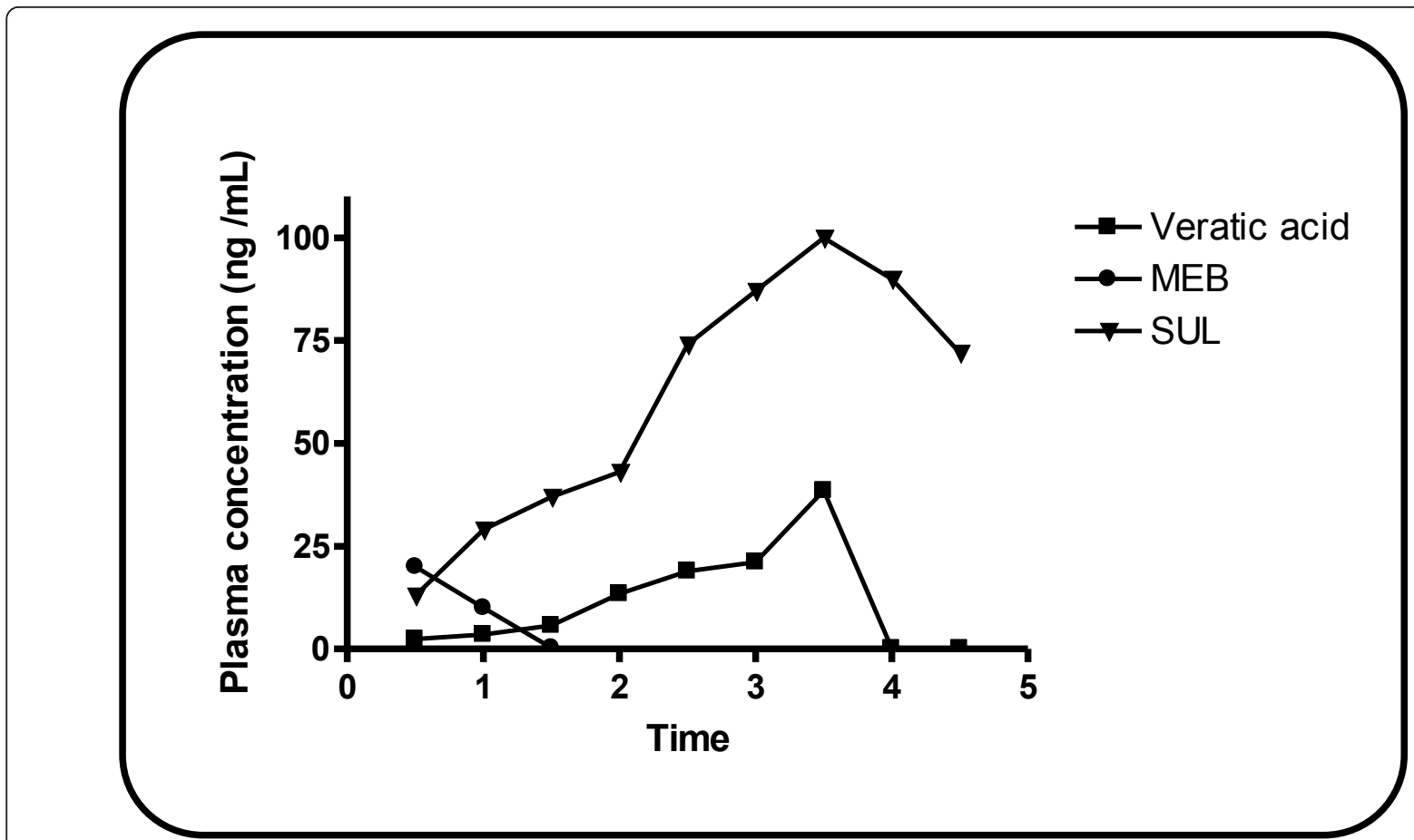

Figure 7 Plasma concentration - time profiles of MEB, veratic acid and SUL after oral administration of Colona ${ }^{\circledR}$ tablets [2 $\times(100 \mathrm{mg}$ MEB + 25 mg SUL)]

\section{Conclusion}

A new simple and sensitive method was explored for the simultaneous determination of MEB and SUL in their combined tablets. The HPLC method using florescence detection, by virtue of its high sensitivity, could be applied to the analysis of both drugs in their co-formulated dosage forms and biological fluids; it was possible to measure concentrations as low as 0.85 and $0.73 \mathrm{ng} /$ $\mathrm{mL}$ for MEB and SUL respectively with good accuracy Moreover, the proposed method allowed therapeutic monitoring of MEB metabolite (veratic acid) in real human plasma without interference with SUL. Moreover, the proposed method is simple, time saving.

\section{Authors' contributions}

MIW designed the proposed method and analyzed the data statistically. MKS and NME proposed, planned and supervised the whole work. NME coordinated the study and modified the text. SMS carried out the experimental work. All authors read and approved the final manuscript.

\section{Competing interests}

The authors declare that they have no competing interests.

Received: 3 October 2011 Accepted: 14 February 2012 Published: 14 February 2012

\section{References}

1. Sweetman SC: Martindale: The complete Drug Reference. 35 edition. The Pharmaceutical Press, London; 2007, 119-692.
2. British Pharmacopoeia Commission: British Pharmacopoeia 2007 The stationary office, UK, London; 2007, (electronic version).

3. Zayed SI: Simultaneous determination of mebeverine hydrochloride and sulpiride using the first derivatives of ratio spectra and chemometric methods. Anal Sci 2005, 21:985-989.

4. El Walily AF, El Gindy A, Bedair MF: Application of first-derivative UVspectrophotometry, TLC-densitometry and liquid chromatography for the simultaneous determination of mebeverine hydrochloride and sulpiride. J Pharm Biomed Anal 1999, 21:535-548.

5. Walash M, Sharaf El-Din M, El-Enany N, Eid M, Shalan Sh: First Derivative synchronous fluorescence spectroscopy for the simultaneous determination of sulpiride and mebeverine hydrochloride in their combined tablets and application to real human plasma. J Fluoresc 2010, 20:1275-1285.

6. Naguib IA, Abdelkawy M: Development and validation of stability indicating HPLC and HPTLC methods for determination of sulpiride and mebeverine hydrochloride in combination. Eur J Med Chem 2010, 45:3719-3725.

7. Naguib IA, Darwish HW: Improved partial least squares models for stability-indicating analysis of mebeverine and sulpiride mixtures in pharmaceutical preparation: A comparative study. Drug test anal 2011.

8. Abdelal A, El-Enany N, Belal FF: Simultaneous determination of sulpiride and its alkaline degradation product by second derivative synchronous fluorescence spectroscopy. Talanta 2009, 80:880-888.

9. Miller JC, Miller JN: Statistics and Chemometrics for Analytical Chemistry. 5 edition. Prince Hall, England; 2005, 256.

10. ICH Harmonized Tripartite Guideline, Validation of analytical procedures: Text and methodology, Q2(R1). [http://www.ich.org/fileadmin/ Public_Web_Site/ICH_Products/Guidelines/Quality/Q2_R1/Step4/ Q2_R1_Guideline.pdf], Current Step 4 Version, Parent Guidlines ON Methodology Dated November 6, 1996, Incorporated in November 2005.

11. Dickinson RG, Baker PV, Franklin ME, Hooper WD: Facile hydrolysis of mebeverine in vitro and in vivo: Negligible circulating concentrations of the drug after oral administration. J Pharm Sci 1991, 80:952-957. 
12. Stockis A, Guelen PJ, de Vos D: Identification of mebeverine acid as the main circulating metabolite of mebeverine in man. J Pharm Biomed Anal 2002, 29:335-340.

doi:10.1186/1752-153X-6-13

Cite this article as: Walash et al: Simultaneous determination of sulpiride and mebeverine by HPLC method using fluorescence detection: application to real human plasma. Chemistry Central Journal 2012 6:13.

\footnotetext{
Publish with ChemistryCentral and every scientist can read your work free of charge

"Open access provides opportunities to our colleagues in other parts of the globe, by allowing anyone to view the content free of charge."

W. Jeffery Hurst, The Hershey Company.

- available free of charge to the entire scientific community

- peer reviewed and published immediately upon acceptance

- cited in PubMed and archived on PubMed Central

- yours - you keep the copyright

Submit your manuscript here:

hubmit your manuscript here:
http://www.chemistrycentral.com/manuscript/<smiles>c1ccccc1</smiles> 